\title{
A Mobile Vehicle-Based Methodology for Dynamic Microclimate Analysis
}

\author{
Ioannis Kousis ${ }^{1,2} \cdot$ Ilaria Pigliautile ${ }^{1,2} \cdot$ Anna Laura Pisello ${ }^{1,2}$ (I)
}

Received: 8 December 2020 / Revised: 11 May 2021 / Accepted: 4 June 2021 / Published online: 1 July 2021

(C) University of Tehran 2021

\begin{abstract}
Accurate monitoring is critical for better understanding cities' microclimate conditions and safeguard citizens' health. Previous studies have performed microclimate analyses of urbanized areas by implementing data from either stable meteorological stations or satellites, or by developing mobile stations. Here, we present a vehicle-based monitoring campaign capable of monitoring both the scalar and directionally dependent variables that regulate the canopy layer environment. Under this framework, we performed a monitoring campaign within an Italian city, and measured simultaneously air temperature $\left( \pm 0.3{ }^{\circ} \mathrm{C} @ 20^{\circ} \mathrm{C}\right)$, relative humidity $\left( \pm 2 \% @ 20^{\circ} \mathrm{C}\right)$, directional shortwave radiation (calibration uncertainty: $<1.8 \%), \mathrm{CO}_{2}( \pm 50 \mathrm{ppm}+2 \%)$ and PM10 $(<1 \%)$ concentration, wind speed $( \pm 3 \% @ 40 \mathrm{~m} / \mathrm{s})$ and direction $\left( \pm 3^{\circ} @ 40\right.$ $\mathrm{m} / \mathrm{s}$ ), and specific location (latitude, longitude and elevation). The presented assessment can be carried out within almost any area that motorized vehicles are allowed to access (e.g. through public transportation vehicles). Its application together with other mobile stations that can specifically assess also pedestrian areas, such as footpaths, urban parks, sidewalks and bike paths, as well as fixed meteorological stations and remote sensing techniques can contribute to a better understanding of microclimate patterns and hence to more efficient urban planning and risk assessments.
\end{abstract}

\section{Article Highlights}

- A novel methodology for monitoring urban environment is presented through transects.

- Advanced mobile drivable van-station is applied to a Mediterranean city in winter.

- Detailed intra-urban variations of urban microclimate variables are presented.

- Both scalar and directionally dependent microclimate variables are monitored.

Keywords Intra urban microclimate $\cdot$ Transect environmental monitoring $\cdot$ Mobile weather station $\cdot$ Anthropogenic heat Urban resilience $\cdot$ Urban heat island

\section{Introduction}

Rural to urban population flow has increased dramatically within recent decades (Gao and O'Neill 2020). In 2016, over half of the world's population was reported to live in urbanized areas, while it is expected that the fraction will

Anna Laura Pisello

anna.pisello@unipg.it

1 CIRIAF-Interuniversity Research Center, University of Perugia, Via G. Duranti 67, 06125 Perugia, Italy

2 Department of Engineering, University of Perugia, Via G. Duranti 97, 06125 Perugia, Italy be increased up to $85 \%$ by 2100 (Nations 2018). Urbanization results typically to high population and building density within cities which inevitably lead to substantial land-use and surface modifications (Liu et al. 2020). In turn, the local microclimate of the cities and the urban environment, in particular, are significantly affected. In fact, urban sprawl is responsible for unpleasant environments within cities and poses threats to human life (Santamouris 2013). For example, increased incidences for morbidity and mortality (Founda and Santamouris 2017), high greenhouse gas emissions (Duan et al. 2019; Keivani et al. 2020) and air pollution (Im et al. 2020; Skrynetska et al. 2018), increased energy consumption (Qiu and Kahn 2018; Abbasian and Souri 2019) and indoor/outdoor thermal discomfort (Li et al. 
2018), low water quality (Tortajada 2020) and incidences of energy poverty (Kousis et al. 2020b) among others are just few of urban sprawl's reported aftermaths.

Under this scenario, several studies have investigated urban microclimate modifications due to city expansion. Different techniques have been implemented for observing the profiles and evaluating the magnitude of various microclimate variables that regulate urban environment. Traditionally, in situ meteorological stations are utilized for measuring variables such as air temperature, humidity and so forth (Santamouris et al. 2007). However, in most cases, the meteorological stations are rather sparsely located and hence the outcomes represent a confined point-wise momentum of the measured variables and not their extended footprint. Remote sensing techniques have also been implemented by retrieving data from satellites, especially for land surface temperature (Zhou et al. 2018), but their low temporal resolution impedes their use for obtaining extensive and real-time intra-urban profiles of microclimate parameters. Therefore, for achieving higher spatial and temporal resolution, several studies have implemented mobile stations capable of monitoring various microclimate parameters (Kim et al. 2019).

In this paper, we present a vehicle-based methodology for intra-urban microclimate monitoring and analysis. Apart from scalar meteorological variables (e.g. temperature and humidity), directionally dependent variables such as shortwave radiation and illuminance can be directionally monitored as well with high accuracy, either the vehicle is in motion or not. We performed a monitoring campaign within the city of Perugia, Italy, which includes a medieval historical center (HCC), newly built residential areas developed near the main train station (UM1-UM2) and several suburban areas (GB1-GB2) that cover the biggest area of the city. The followed path of the monitoring campaign covered all these areas. Here, we demonstrate the outcomes of the monitoring campaign concerning air temperature and absolute humidity as scalar variables and shortwave radiation as vectorial variable. Both are critical determinants of the outdoor urban environment and highly affect citizens' well-being. For example, high outdoor inner-city temperature is a primary indicator of outdoor discomfort that may put citizens' health in serious danger (Santamouris 2013). Similarly, absolute humidity is lately regarded from epidemiologist as an indicator of influenza virus, e.g. COVID-19, related transmission levels (Rashed et al. 2020). Moreover, $\mathrm{CO}_{2}$ and PM10 concentrations, averaged shortwave radiation, wind speed, air pressure and dew-point temperature profiles across the following pathway are presented at a local zone-scale, i.e. green belt, urban modern and historical city center, and correlated accordingly for identifying possible primary relationships through distance covariance.

\section{Methods}

The mobile monitoring station reported here can measure simultaneously air temperature (accuracy: $\pm 0.3{ }^{\circ} \mathrm{C} @ 20$ $\left.{ }^{\circ} \mathrm{C}\right)$, relative humidity $\left( \pm 2 \% @ 20{ }^{\circ} \mathrm{C}\right)$, shortwave radiation (spectral range: $285-3000 \mathrm{~nm}$, calibration uncertainty: $<1.8 \%$ ), illuminance (range: $0-10,0001 x$ ), dewpoint temperature, $\mathrm{CO}_{2}$ (range: 0-2000 ppm, accuracy: $\pm 50 \mathrm{ppm}$ $+2 \%$ of measured value) and PM10 (resolution: 1/4096, accuracy: < 1\%) concentration, and speed (accuracy: \pm 3\%@ $40 \mathrm{~m} / \mathrm{s}$, resolution: $0.001 \mathrm{~m} / \mathrm{s}$ ) and direction (Accuracy: $\pm 3^{\circ} @ 40 \mathrm{~m} / \mathrm{s}$, resolution: $1^{\circ}$ ) of wind (Kousis et al. 2021). All sensors are calibrated and placed on five specifically designed hosting-units. All units are positioned on the two façades of the vehicle, i.e. on the top and the back sides to minimize shadowing effects (Fig. 1).

Shortwave radiation and illuminance are measured each by five different sensors oriented towards (1) the sky, (2) the street, the (3) right, the (4) left and the (5) backside of the vehicle. Since, however, the presented monitoring campaign was carried out during daytime, measurements of illuminance are not presented herein. Air temperature is measured by five different sensors, each placed in each unit and subsequently a mean value is calculated. In addition, data concerning the specific position, i.e. longitude, latitude and altitude, of the station were obtained by a Global Position System embedded in the sensor of wind speed and direction for correcting direction misalignments due to the vehicle's motion.

We mapped out a monitoring path within the city of Perugia, Italy. According to the Koppen and Geiger classification (Beck et al. 2018), Perugia is classified as Cfa and is characterized by humid subtropical climate conditions. The pathway is almost circular and it ends where it starts. It passes through different types of urban morphology, land-use, and human activity. Therefore, we divided the path to sub-areas according to their particular characteristics. We identified three different sub-zones within the city, i.e. the main suburb area of Perugia, the recent urban neighbourhood close to the main train station and the center area of the city. Afterwards, we performed monitoring campaigns during the winter period of 2020. Subsequently, we reckoned the averaged January and averaged Winter day profiles with data retrieved from the meteorological station of the University of Perugia, located in close proximity to the starting/ending point of the monitoring campaign. (Kousis et al. 2020a). Here, we present the outcomes of a day-time monitoring campaign, carried out on 20th of January, since the difference among the temperature profile of this day and the profiles of the averaged January and averaged Winter days were found be statistically insignificant ( $p$-value $>0.05$ ) (Table1), 
Fig. 1 The presented mobile monitoring station

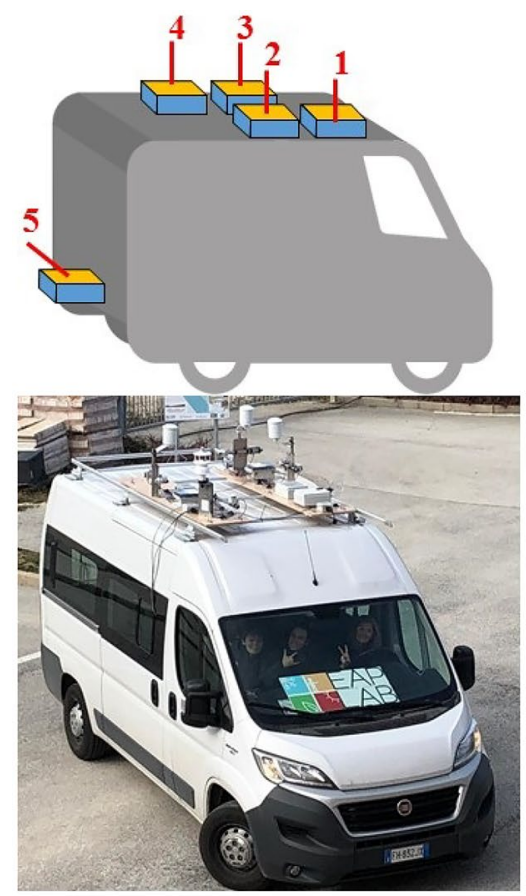

1 - Front unit

Air temperature, relative humidity, shortwave radiation, illuminance, wind speed and direction, $\mathrm{CO}_{2}$, GPS

2 - Right side unit

Air temperature, shortwave radiation, illuminance

3 - Left side unit

Air temperature, shortwave radiation, illuminance, PM10

\section{4 - Back unit}

Air temperature, shortwave radiation, illuminance

5 - Bottom unit

Air temperature, shortwave radiation, illuminance

Table 1 Wilcoxon test among the day of the presented monitoring, and the averaged January and Winter days of the same year

\begin{tabular}{|c|c|c|c|c|c|c|}
\hline & \multicolumn{3}{|c|}{ January day (averaged) } & \multicolumn{3}{|c|}{ Winter day (averaged) } \\
\hline & $p$-val & Eff. size & $\Delta T_{\max }$ & $p$-val & eff. size & $\Delta T_{\max }$ \\
\hline $20 / 01 / 2020$ & 0.36 & 0.187 & -0.6 & 0.84 & 0.254 & -0.9 \\
\hline
\end{tabular}

$\Delta T_{\max }=T_{20 / 01 / 2020}-T_{\text {January } / \text { Winter day }}$

with respect to Wilcoxon matched-pairs signed rank test (Bagkavos and Patil 2021). Therefore, we considered this day as a typical winter day. Moreover, this day was also characterized by clear sky conditions and relatively stable boundary conditions, e.g. low wind speed and ambient temperature variation. The monitoring campaign started at 12:38 and finished at 13:50.

All measurements are taken at the same time-stamp every $10 \mathrm{~s}$. We ensured accurate measurements of air temperature by aspirating the corresponding sensors by vehicle's motion, and by positioning them inside a specifically designed radiation shield. Nevertheless, vehicle's speed affects intrinsically the accuracy of mobile measurements. Oke et al. (2017) recommends a vehicle speed around $10 \mathrm{~km} / \mathrm{h}$. At the same time, according to Taha et al. (2018), data obtained on vehicle speed below $10 \mathrm{~km} / \mathrm{h}$ should be discarded, for minimizing the effects of anthropogenic heating changes. Several relevant studies report vehicle speed higher than $30 \mathrm{~km} / \mathrm{h}$ (Hart and Sailor 2009; Soltani and Sharifi 2017; Jacobs et al. 2019). Here, to obtain high spatial resolution, we maintained vehicle's speed constantly around $20 \mathrm{~km} / \mathrm{h}$ and hence the measurements of all variables were taken approximately every $50 \mathrm{~m}$. Another limitation that mobile monitoring is typically prone to is the need of applying correction methods to the parameters that may be affected by the variation of weather boundaries due to time-elapsed, especially when the duration of the campaign is well above $1 \mathrm{~h}$ (Taha et al. 2018). Here, no time-correction method was applied. Instead, to minimize the time-dependency of the data, the present monitoring campaign was systematized to last approximately one hour and performed under rather stable boundary meteo-conditions, i.e. the maximum air temperature range measured by the meteorological station of the University of Perugia during the campaign was $0.2^{\circ} \mathrm{C}$ and the corresponding standard deviation was 0.05 ${ }^{\circ} \mathrm{C}$, while the wind speed was almost always well below $10 \mathrm{~m} / \mathrm{s}$. Effects on the data owing to traffic, shadowing and other unforeseen random events that may occur due to the contingent nature of urban areas are also possible. If apparent, however, their magnitude could be evaluated and if needed mitigated, by selecting a proper scale-analysis, e.g. a neighbourhood-scale assessment. 
Table 2 Difference of the mean temperature values in-between the defined zones (measured by the mobile station) and the simultaneous mean values measured by the meteorological station of the University of Perugia

\begin{tabular}{llllll}
\hline & $\mathrm{GB} 1$ & $\mathrm{UM} 1$ & $\mathrm{HCC}$ & $\mathrm{UM} 2$ & $\mathrm{~GB} 2$ \\
\hline$\Delta T=T_{\text {mobile }}-T_{\text {fixed }}$ & $0.1{ }^{\circ} \mathrm{C}$ & $0.0^{\circ} \mathrm{C}$ & $-0.9^{\circ} \mathrm{C}$ & $0.2^{\circ} \mathrm{C}$ & $0.3{ }^{\circ} \mathrm{C}$ \\
\hline
\end{tabular}

\section{Results}

Figure 2 illustrates the profiles of air temperature and absolute humidity recorded by the presented monitoring station together with the air temperature measured by the meteorological station of University of Perugia (Fig. 2a), a corresponding map representation wherein color represents the temperature and size the absolute humidity (Fig. 2b) and a directional representation of Shortwave radiation at specific spots across the followed pathway (Fig. 2c). A first understanding concerning the spatial tendency of both selected variables can be derived from Fig. 2b. Overall, the city center was found a bit cooler than the adjacent areas. The lowest value of temperature was recorded within the $\mathrm{HCC}\left(7.6^{\circ} \mathrm{C}\right)$ while the highest was recorded in the GB2 $\left(9.5^{\circ} \mathrm{C}\right)$. On the other hand, the profile of absolute humidity is characterized by rather small deviations (standard deviation $= \pm 0.1 \mathrm{~g} / \mathrm{m}^{3}$ ). This
Fig. 2 a Air temperature and absolute humidity profiles, $\mathbf{b}$ pathway of the monitoring campaign and spatial distribution of air temperature and absolute humidity, c directional distribution of Shortwave radiation in $\mathrm{w} / \mathrm{m}^{2}$
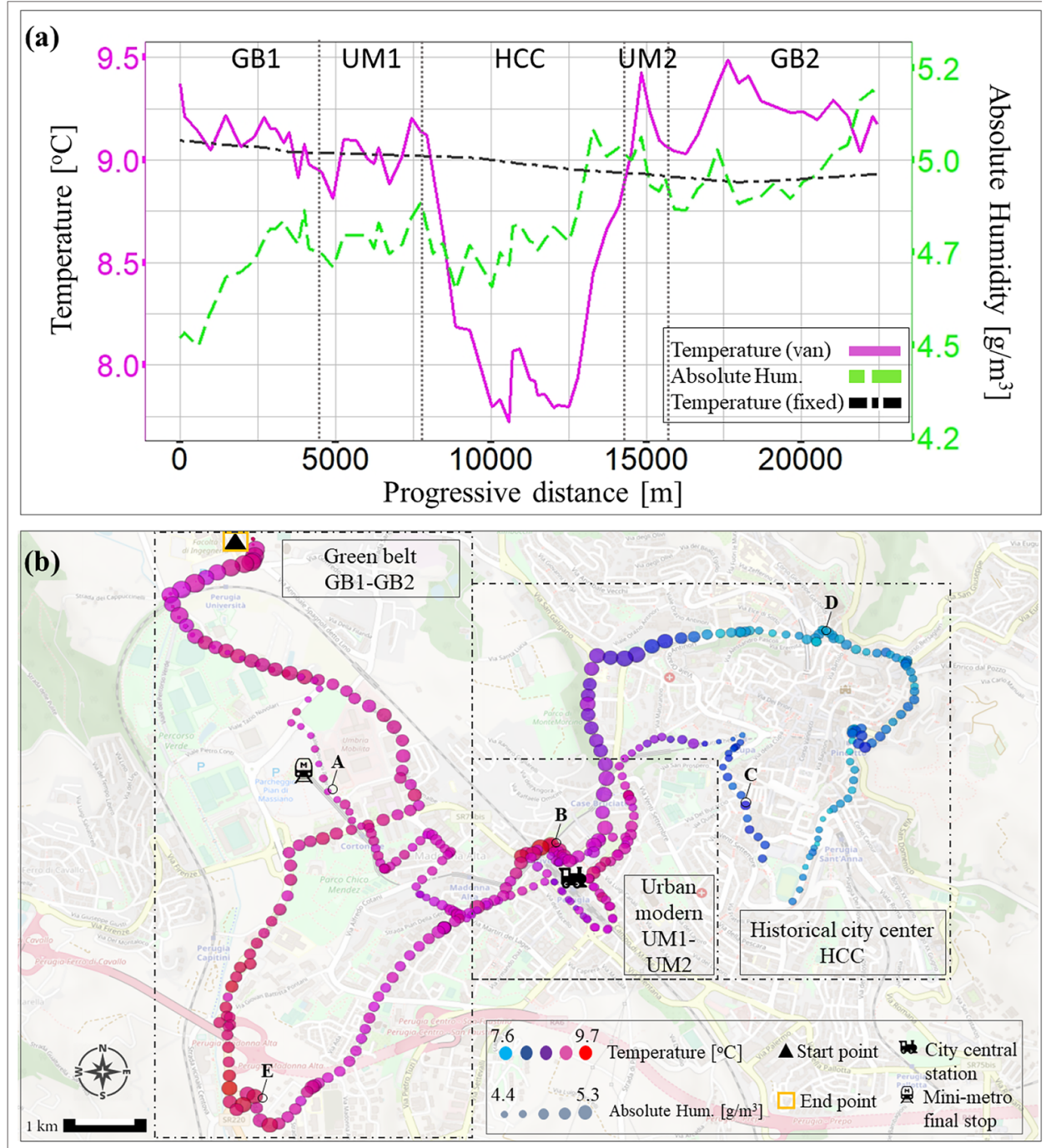

(c)

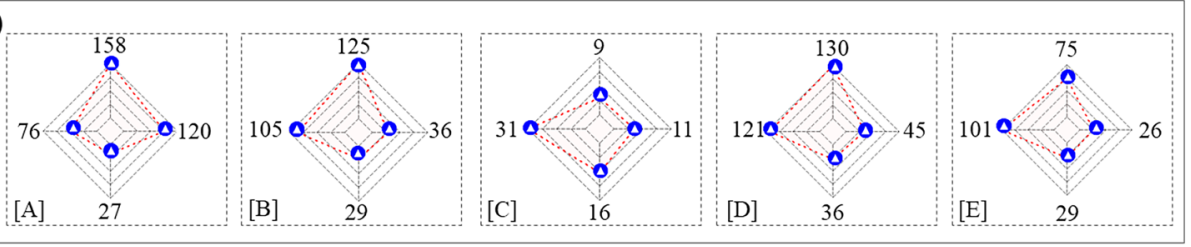


is also evident in Fig. 2a. However, a small drop can be seen as entering to the city center, which is likely due to the absence of greenery or water surfaces. Moreover, the decrease (up to $1.6^{\circ} \mathrm{C}$ ) and rise (up to $1.9^{\circ} \mathrm{C}$ ) of air temperature as getting in and out, respectively, from the historical center is also evident. This variation experienced within the same city (less than $3 \mathrm{~km}$ as the crow flies) cannot be captured by a unique fixed meteorological station, as the one here presented as reference and located at the monitoring route starting/ending point (Fig. 2b). Indeed, mean temperature gaps of $0.1{ }^{\circ} \mathrm{C},-0.9^{\circ} \mathrm{C}, 0.2$ ${ }^{\circ} \mathrm{C}$ and $0.3{ }^{\circ} \mathrm{C}$ are observed for the crossed areas with respect to the reference (GB1, HCC, UM2 and GB2 areas, respectively) (Table 2). This indicates a possible inability of fixed meteorological stations to capture intra-urban variabilities, that is strictly related to the specific position of the station. For instance, no certified meteorological station is reported within the center area of Perugia. A fine-grain fix stations network would be needed to catch the observed intra-urban variability which is an expensive solution from different perspectives (sensors purchase, installation, and maintenance costs of a large number of weather stations). The application of mobile monitoring techniques may not only offer insights to such variations, but also identify key-locations and the optimum number for the strategic development of fixed stations, and further support intra-urban monitoring being complementary to long-term fix monitoring.

The HCC of Perugia is surrounded by medieval walls and is characterized by narrow and well-shaded streets. Most of these areas are not accessible to motorised vehicles. Hence, incident shortwave radiation can be significantly lower as compared to the GB1-GB2 and UM1-UM2 areas which are characterized by wider open air spaces. In fact, as it can be seen in Fig. 2c, the distribution of shortwave radiation may substantially vary within the very same city in terms of both inner-city location and direction. For instance, at spots A and B located within the open-air areas of the GB1 and near to UM1 respectively the vertical incident short-wave radiation dominates other, while at the well-shaded spot $\mathrm{C}$ the highest fraction of incident shortwave radiation comes from rightward. Similarly, depending on the specific location within the city significant portion of shortwave radiation may come from the left (spot A) or right side of the specifically monitored canyon (spots B, D, E).
Fig. 3 a $\mathrm{CO}_{2}$ concentration in ppm, b PM10 concentration in $\mathrm{ppm}, \mathbf{c}$ average shortwave radiation $\mathrm{w} / \mathrm{m}^{2}, \mathbf{d}$ wind speed in $\mathrm{m} / \mathrm{s}$, e air pressure in $\mathrm{Pa}$, $\mathbf{f}$ dew-point temperature in ${ }^{\circ} \mathrm{C}, \mathbf{g}$ distance covariance coefficients, scatter plot and 2D Kernel density estimation in between the measured variables. $T$ is temperature, $\mathrm{AH}$ is absolute humidity, SR is averaged shortwave radiation and WS is wind speed
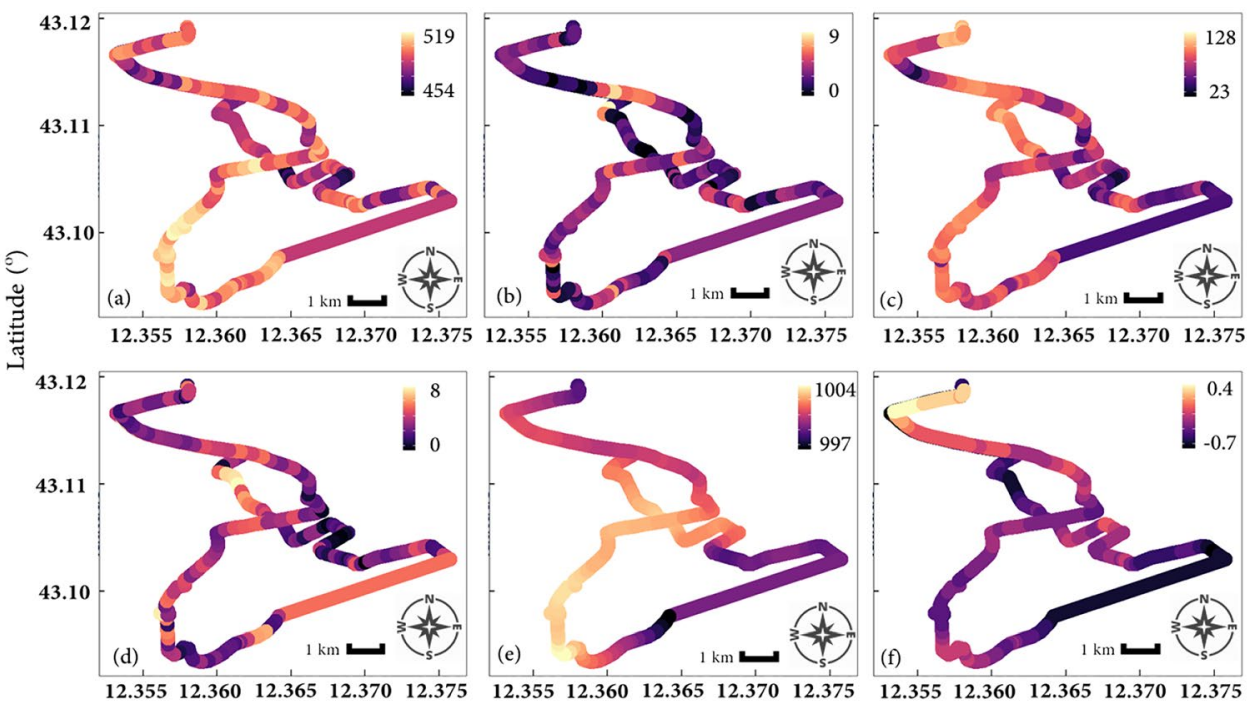

$\begin{array}{lllll}12.355 & 12.360 & 12.365 & 12.370 & 12.375\end{array}$
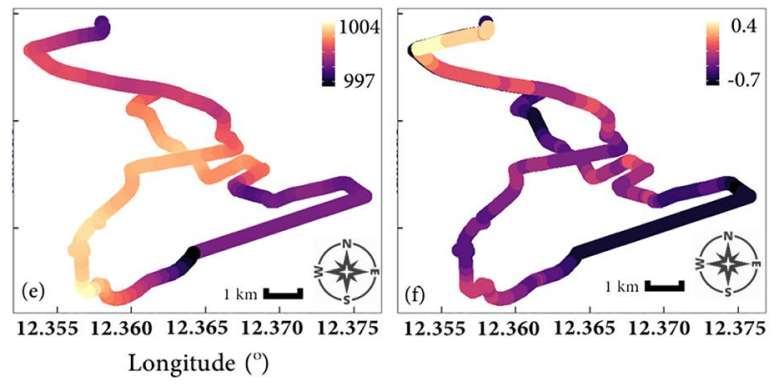

$\begin{array}{ccccc}12.355 & 12.360 & 12.365 & 12.370 & 12.375\end{array}$ Longitude $\left({ }^{\circ}\right)$

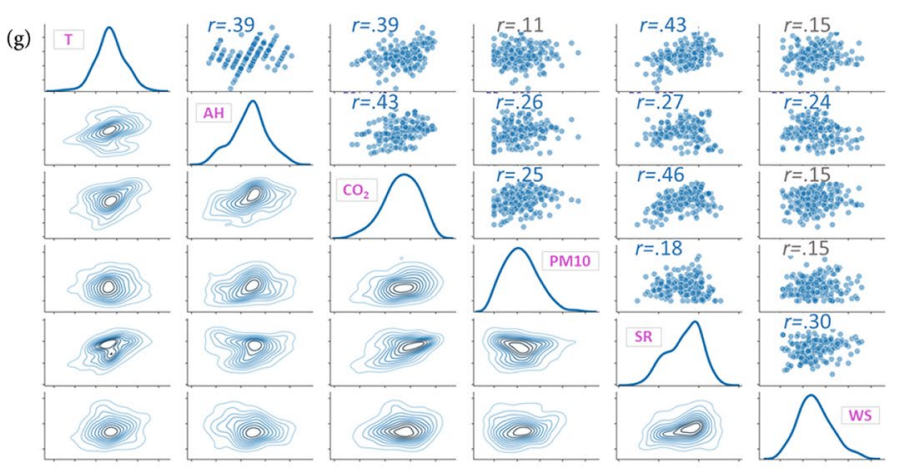

Green Belt (GB1, GB2) 
Figures 3, 4, and 5 illustrate the point-wise footprints of $\mathrm{CO}_{2}$ concentration (a), PM10 concentration (b), averaged shortwave radiation (c), wind speed (d), air pressure (e) and dew-point temperature (f), as well as the outcomes of the distance covariance applied to the measured parameters (g) across the the GB, UM and HCC areas, respectively. The highest vales of shortwave radiation and wind speed were recorded within the suburb area owing to the large open-air areas. On the other hand, the highest values of $\mathrm{CO}_{2}$ and PM10 were recorded within the area close to the train station, which is typically characterised by high vehicular traffic and anthropogenic action during the daytime, as compared to the other city zones. Overall, the city center is characterised with the lowest values of almost all the monitored parameters, most likely due to the shadowed narrow streets, that are well covered by the high and circular medieval walls and the limited vehicular traffic as compared to the other city-zones. Furthermore, the primary relationships among the measured parameters within each sub-area were assessed through distance covariance (Székely and Rizzo 2013). The corresponding coefficients $(r)$ are displayed in blue when $p$ value $\leq 0.05$ and are considered statistically significant, and in grey when $p$ value $>$
0.05 and considered statistically insignificant. The diagonal comprises the rug plots, the part above the diagonal comprises the scatter plots and the part below the diagonal comprises contours of a 2D Kernel density estimation. The resulted coefficients are low to moderate, i.e. they range from 0.11 to 0.62 . The most significant relationships were found between $\mathrm{CO}_{2}$ concentration and shortwave radiation within the center area $(r=0.62, p$ value $<0.05)$ and train area $(r=0.50, p$ value $<0.05)$.

\section{Discussion and Future Outlook}

Urbanization has gradually became a critical issue of environmental degradation that poses a great challenge to social development, citizens' well-being and cities as an ecological niche. The increasing population density and the corresponding demands lead to natural-to-urban land alterations that modify the patterns of the microclimate parameters of urban environments (Yun et al. 2020). Urban and urbanized areas are prone to local energy balance modifications that in turn affect outdoor and indoor conditions and hence the citizens' life quality. For instance, excessively high ambient
Fig. 4 a $\mathrm{CO}_{2}$ concentration in ppm, b PM10 concentration in $\mathrm{ppm}, \mathbf{c}$ average shortwave radiation $\mathrm{w} / \mathrm{m}^{2}, \mathbf{d}$ wind speed in $\mathrm{m} / \mathrm{s}$, e air pressure in $\mathrm{Pa}, \mathbf{f}$ dew-point temperature in ${ }^{\circ} \mathrm{C}, \mathbf{g}$ distance covariance coefficients, scatter plot and 2D Kernel density estimation in between the measured variables. $T$ is temperature, $\mathrm{AH}$ is absolute humidity, SR is averaged shortwave radiation and WS is wind speed

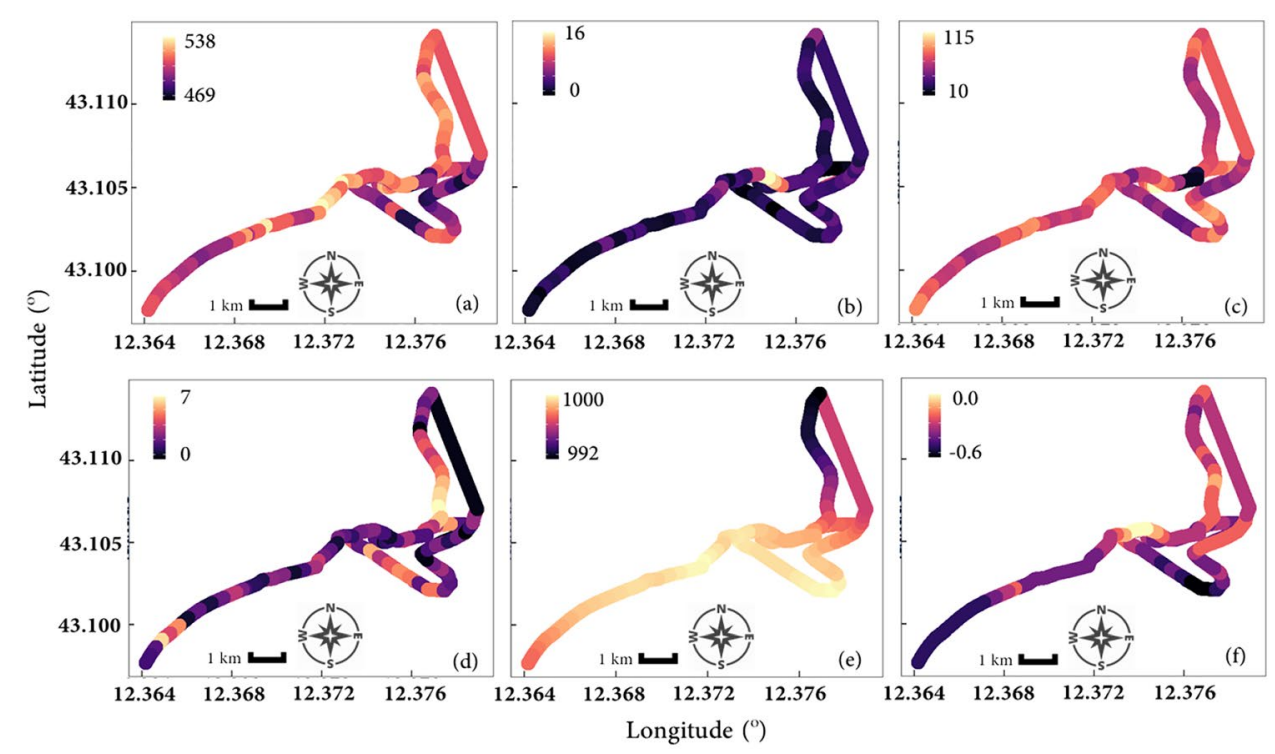

(g)

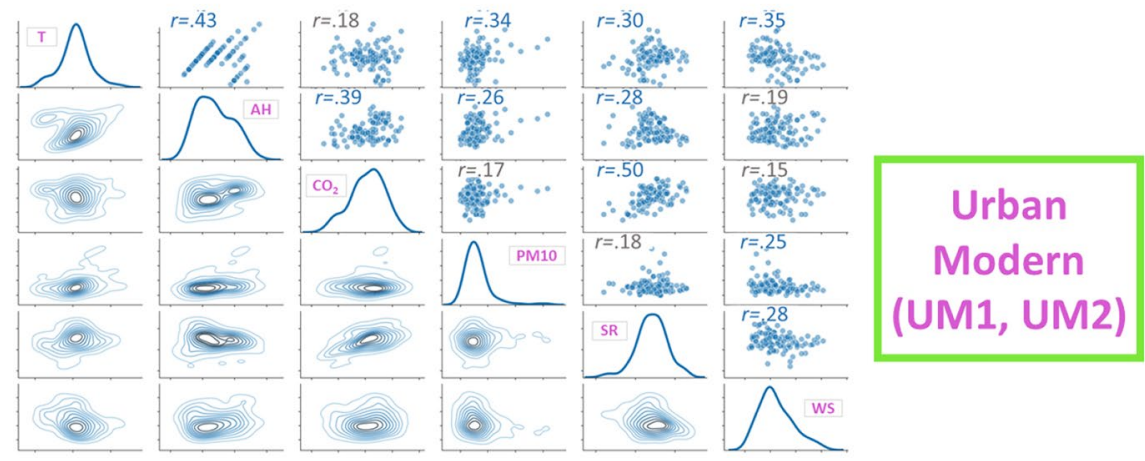


Fig. 5 a CO 2 concentration in ppm, b PM10 concentration in $\mathrm{ppm}, \mathbf{c}$ average shortwave radiation $\mathrm{w} / \mathrm{m}^{2}, \mathbf{d}$ wind speed in $\mathrm{m} / \mathrm{s}$, e air pressure in $\mathrm{Pa}, \mathbf{f}$ dew-point temperature in ${ }^{\circ} \mathrm{C}, \mathbf{g}$ distance covariance coefficients, scatter plot and 2D Kernel density estimation in between the measured variables. $T$ is temperature, $\mathrm{AH}$ is absolute humidity, SR is averaged shortwave radiation and WS is wind speed
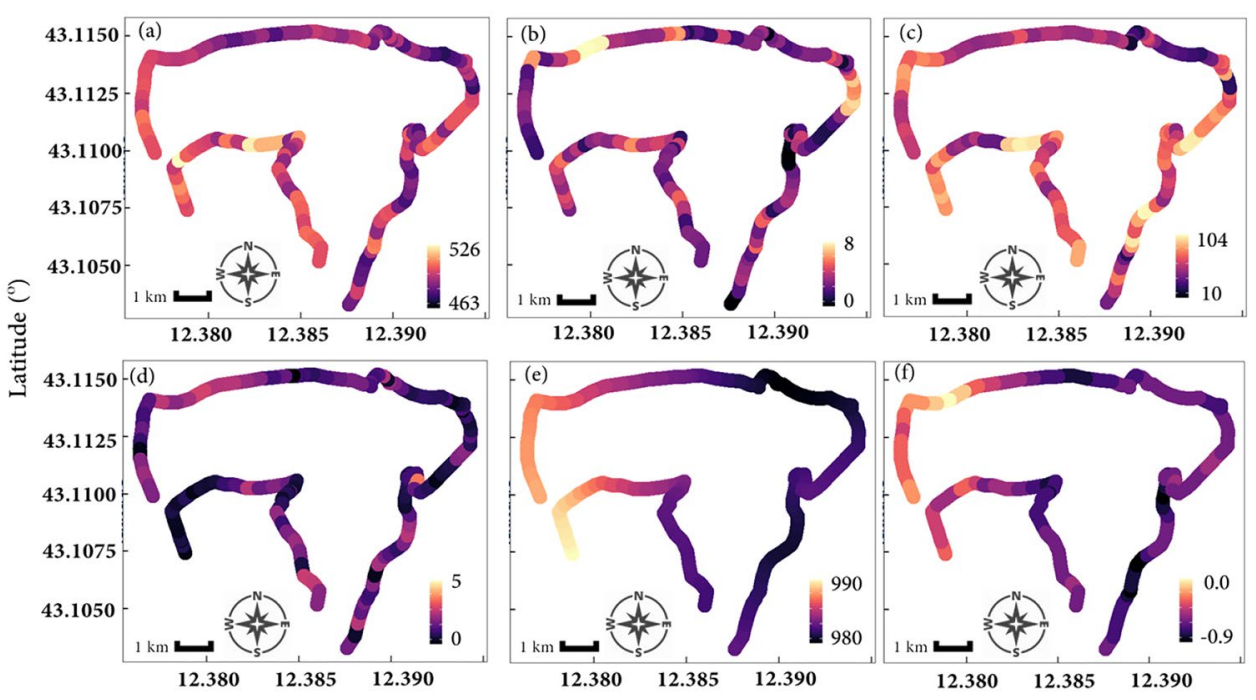

$\begin{array}{lll}12.380 & 12.385 & 12.390\end{array}$

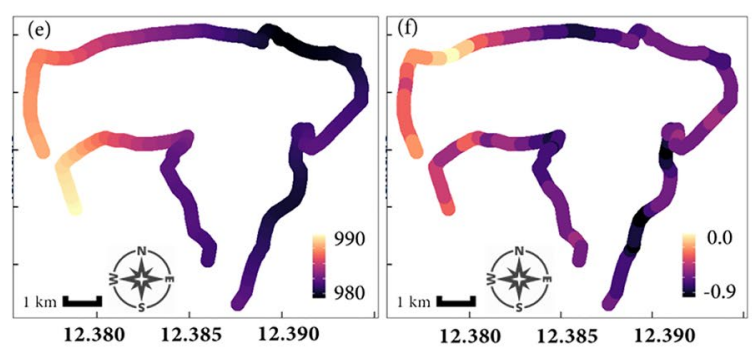

Longitude $\left({ }^{\circ}\right)$
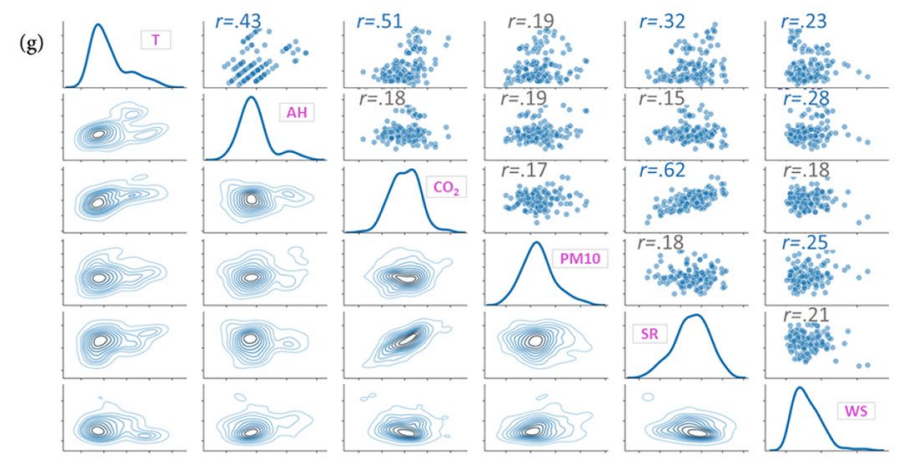

and surface temperatures, i.e. Urban Heat Island (UHI) effect (Kousis and Pisello 2020), are reported during the summer period in hundreds of cities. UHI, together with the shortage of green and water surfaces, alters the fluxes of turbulent sensible and latent heat, as well as humidity profiles (Arnfield 2003). Wind and ambient pressure profiles are also altered due to lack of efficient urban planning (Grawe et al. 2013), which, furthermore, in many cases turn carbon sinks to carbon sources (Han et al. 2017). In addition, anthropogenic activity such as public and private transportation, working needs and spaces, result in exacerbated energy consumption, air impairment, hazardous wastes, and carbon emissions (Boehme et al. 2015). In fact, according to UN habitat, even though urban areas cover approximately $2 \%$ of Earth's surface, they account for $78 \%$ of the world's energy consumption and are responsible for more than $60 \%$ of greenhouse gas emissions (Habitat 2013). At the same time, in 2016, the World Health Organization reported that $91 \%$ of the world population is exposed to air pollution incidences (WHO 2016). The effects of urbanization are usually interconnected and if not addressed accordingly can seriously threat environmental health. For instance, high ambient temperatures are found to increase morbidity, mortality (Tan et al. 2010) and energy poverty incidences (Kousis et al. 2020b), while exposure to high concentration of particulate matter can also pose serious threat to citizens' wellbeing and health, e.g stroke, heart disease, lung cancer, and chronic or acute respiratory diseases (Stockfelt et al. 2017; Raaschou-Nielsen et al. 2013).

An in-depth evaluation of the parameters that regulate urban environment and hence safeguard urban environmental health and sustainability need to be undertaken under a multidisciplinary approach and improved methods of health risk assessment. Static observation stations provide a substantial information with respect to environmental parameters at meso and global scale. Yet, a more sophisticated investigation at the micro-scale is needed for efficiently evaluating the intra-urban characteristics of a city that are typically characterized by significant heterogeneity and structural complexity. Under this framework, here, we present a vehicle-based methodology for monitoring and representing the intra-urban variations of the main microclimate parameters within the urban canopy, by simultaneously monitoring both scalar and directionally dependent variables with high spatial resolution. The present methodology can be applied to almost any urban area, since all the monitoring components utilised here can be easily re-attached to almost any other similar configuration. The acquisition of 
the specific vehicle speed during the monitoring campaign, as well as the design of elapsed time-correction protocols when the duration of the campaign is well above one hour should be considered as a crucial future outlook for improving the reliability and accuracy of the measurements. In addition, future research should optimise the monitoring path design with respect to the specific land use/land cover and overall urban planning of the investigated city. Intraurban patterns of the microclimate parameters should be further assessed under both seasonal and annual scales and exploited under geographic information system framework. Under this scenario, we believe that a holistic approach that comprises data collected by the presented methodology and data collected from other mobile micro-scale stations, such as helmets (Pigliautile and Pisello 2018), trolleys (Vasilikou and Nikolopoulou 2020) and carts (Middel and Krayenhoff 2019) in conjunction with stable stations and satellite data, will exploit the understanding of the urban microclimate and the corresponding environmental quality with respect to the specific local morphology, anthropogenic action, urban planning and temporal weather conditions.

Acknowledgements Author's acknowledgments are due to the European Union's Horizon 2020 program under Grant agreement no .678407765057 (ZEROPLUS).

\section{References}

Abbasian E, Souri A (2019) The inefficiency of energy pricing policy: the case of Iran. Int J Environ Res 13(6):943-950

Arnfield AJ (2003) Two decades of urban climate research: a review of turbulence, exchanges of energy and water, and the urban heat island. Int J Climatol J R Meteorol Soc 23(1):1-26

Bagkavos D, Patil PN (2021) Improving the wilcoxon signed rank test by a kernel smooth probability integral transformation. Stat Prob Lett 171:109026 (ISSN 0167-7152). https://doi.org/10. 1016/j.spl.2020.109026, https://www.sciencedirect.com/scien ce/article/pii/S0167715220303291

Beck HE, Zimmermann NE, McVicar TR, Vergopolan N, Berg A, Wood EF (2018) Present and future köppen-geiger climate classification maps at 1-km resolution. Sci Data 5:180214

Boehme P, Berger M, Massier T (2015) Estimating the building based energy consumption as an anthropogenic contribution to urban heat islands. Sustain Cities Soc 19:373-384

Desa, U. N. (2018). Revision of world urbanization prospects. UN Dept Econ Soc Aff 16

Duan J, Ma Z, Peili W, Xoplaki E, Hegerl G, Li L, Schurer A, Guan D, Chen L, Duan Y et al (2019) Detection of human influences on temperature seasonality from the nineteenth century. Nature Sustain 2(6):484-490

Founda D, Santamouris M (2017) Synergies between urban heat island and heat waves in athens (greece), during an extremely hot summer (2012). Sci Rep 7(1):1-11

Gao J, O'Neill BC (2020) Mapping global urban land for the 21st century with data-driven simulations and shared socioeconomic pathways. Nature Commun 11(1):1-12
Grawe D, Thompson HL, Salmond JA, Cai X-M, Schlünzen KH (2013) Modelling the impact of urbanisation on regional climate in the greater london area. Int J Climatol 33(10):2388-2401

Habitat UN (2013) State of the world's cities 2012/2013: prosperity of cities. Routledge, England

Han J, Meng X, Zhou X, Yi B, Liu M, Xiang W-N (2017) A long-term analysis of urbanization process, landscape change, and carbon sources and sinks: a case study in china's yangtze river delta region. J Clean Prod 141:1040-1050

Hart MA, Sailor DJ (2009) Quantifying the influence of land-use and surface characteristics on spatial variability in the urban heat island. Theor Appl Climatol 95(3):397-406

Im JY, Kim B, Kim HY, Lee MJ, Jeon DY, Ryu JS, Yun DS, Jang YC, Lee CS (2020) A study on the characteristics of hazardous pollutant emissions in korea from 2007 to 2016. Int J Environ Res 14(3):335-346

Jacobs C, Singh T, Gorti G, Iftikhar U, Saeed S, Syed A, Abbas F, Ahmad B, Bhadwal S, Siderius C (2019) Patterns of outdoor exposure to heat in three south Asian cities. Sci Total Env 674:264-278

Keivani E, Abbaspour M, Abedi Z, Ahmadian M (2020) Promotion of low-carbon economy through efficiency analysis: a case study of a petrochemical plant. Int J Environ Res 2020:1-11

Kim Y-J, Kim B-J, Shin Y-S, Kim H-W, Kim G-T, Kim S-J (2019) A case study of environmental characteristics on urban road-surface and air temperatures during heat-wave days in seoul. Atmos Oceanic Sci Lett 12(4):261-269

Kousis I, Anna LP (2020) For the mitigation of urban heat island and urban noise island: two simultaneous sides of urban discomfort. Environ Res Lett 15(10):103004

Kousis I, Claudia F, Luca E, Pisello AL (2020a) Using bio-oils for improving environmental performance of an advanced resinous binder for pavement applications with heat and noise island mitigation potential. Sustain Energy Technol Assess 39:100706 (ISSN 2213-1388). https://doi.org/10.1016/j.seta.2020.100706, https:// www.sciencedirect.com/science/article/pii/S2213138820300825

Kousis I, Marina L, Vasileios N, Margarita-Niki A, Joanna R (2020b) An analysis of the determining factors of fuel poverty among students living in the private-rented sector in Europe and its impact on their well-being. Energy Sources Part B Econ Plan Policy 15(2):113-135

Kousis I, Ilaria P, Laura PA (2021) Intra-urban microclimate investigation in urban heat island through a novel mobile monitoring system. Sci Rep 11:9732. https://doi.org/10.1038/ s41598-021-88344-y

Li J, Chen YD, Gan TY, Lau N-C (2018) Elevated increases in humanperceived temperature under climate warming. Nature Clim Change 8(1):43-47

Liu X, Huang Y, Xu X, Li X, Li X, Ciais P, Lin P, Gong K, Ziegler AD, Chen A et al (2020) High-spatiotemporal-resolution mapping of global urban change from 1985 to 2015 . Nature Sustain 2020:1-7

Middel A, Krayenhoff ES (2019) Micrometeorological determinants of pedestrian thermal exposure during record-breaking heat in tempe, arizona: Introducing the marty observational platform. Sci Total Env 687:137 - 151 (ISSN 0048-9697). https://doi. org/10.1016/j.scitotenv.2019.06.085, URL http://www.sciencedir ect.com/science/article/pii/S0048969719326531

Oke TR, Mills G, Christen A, Voogt JA (2017) Urban climates. Cambridge University Press, Cambridge

Pigliautile I, Pisello AL (2018) A new wearable monitoring system for investigating pedestrians' environmental conditions: Development of the experimental tool and start-up findings. Sci Total Env 630:690-706 (ISSN 0048-9697). https://doi.org/10.1016/j. scitotenv.2018.02.208, http://www.sciencedirect.com/science/artic le/pii/S0048969718306077

Qiu Y, Kahn ME (2018) Better sustainability assessment of green buildings with high-frequency data. Nature Sustain 1(11):642-649 
Raaschou-Nielsen O, Andersen ZJ, Beelen R, Samoli E, Stafoggia M, Weinmayr G, Hoffmann B, Fischer P, Nieuwenhuijsen MJ, Brunekreef B et al (2013) Air pollution and lung cancer incidence in 17 european cohorts: prospective analyses from the european study of cohorts for air pollution effects (escape). Lancet Oncol 14(9):813-822

Rashed EA, Kodera S, Gomez-Tames J, Hirata A (2020) Influence of absolute humidity, temperature and population density on COVID-19 spread and decay durations: multi-prefecture study in Japan. Int J Environ Res Public Health 17(15):5354

Santamouris M (2013) Using cool pavements as a mitigation strategy to fight urban heat island-a review of the actual developments. Renew Sustain Energy Rev 26:224-240 (ISSN 1364-0321). https://doi.org/10.1016/j.rser.2013.05.047, http://www.sciencedir ect.com/science/article/pii/S136403211300350X

Santamouris M, Paraponiaris K, Mihalakakou G (2007) Estimating the ecological footprint of the heat island effect over Athens, Greece. Clim Change 80(3-4):265-276

Skrynetska I, Ciepał R, Kandziora-Ciupa M, Barczyk G, NadgórskaSocha A (2018) Ecophysiological responses to environmental pollution of selected plant species in an industrial urban area. Int J Environ Res 12(2):255-267

Soltani A, Sharifi E (2017) Daily variation of urban heat island effect and its correlations to urban greenery: a case study of adelaide. Front Architect Res 6(4):529-538

Stockfelt L, Andersson EM, Molnár P, Gidhagen L, Segersson D, Rosengren A, Barregard L, Sallsten G (2017) Long-term effects of total and source-specific particulate air pollution on incident cardiovascular disease in gothenburg, Sweden. Environ Res 158:61-71

Székely Gábor J, Rizzo Maria L (2013) The distance correlation $\mathrm{t}$-test of independence in high dimension. J Multivariate Anal
117:193-213 (ISSN 0047-259X). https://doi.org/10.1016/j.jmva. 2013.02.012, https://www.sciencedirect.com/science/article/pii/ S0047259X13000262

Taha H, Levinson R, Mohegh A, Gilbert H, Ban-Weiss G, Chen Sharon (2018) Air-temperature response to neighborhood-scale variations in albedo and canopy cover in the real world: fine-resolution meteorological modeling and mobile temperature observations in the los angeles climate archipelago. Climate 6(2):53

Tan J, Zheng Y, Tang X, Guo C, Li L, Song G, Zhen X, Yuan D, Kalkstein AJ, Li F et al (2010) The urban heat island and its impact on heat waves and human health in shanghai. Int J Biometeorol 54(1):75-84

Tortajada C (2020) Contributions of recycled wastewater to clean water and sanitation sustainable development goals. NPJ Clean Water $3(1): 1-6$

Vasilikou C, Nikolopoulou M (2020) Outdoor thermal comfort for pedestrians in movement: thermal walks in complex urban morphology. Int J Biometeorol 64(2):277-291

WHO (2016) Ambient (outdoor) air pollution

Yun GY, Ngarambe J, Duhirwe PN, Ulpiani G, Paolini R, Haddad S, Vasilakopoulou K, Santamouris M (2020) Predicting the magnitude and the characteristics of the urban heat island in coastal cities in the proximity of desert landforms. the case of sydney. Sci Total Env 709:136068 (ISSN 0048-9697). https://doi.org/10. 1016/j.scitotenv.2019.136068, https://www.sciencedirect.com/ science/article/pii/S0048969719360644

Zhou D, Bonafoni S, Zhang L, Wang R (2018) Remote sensing of the urban heat island effect in a highly populated urban agglomeration area in east china. Sci Total Env 628-629:415-429 (ISSN 00489697). https://doi.org/10.1016/j.scitotenv.2018.02.074, http:// www.sciencedirect.com/science/article/pii/S0048969718304649 